\title{
Article \\ Grafting of Acrylic Membrane Prepared from Fibers Waste for Dyes Removal: Methylene Blue and Congo Red
}

\author{
Ahmed Labena ${ }^{1, *}$, Ahmed E. Abdelhamid ${ }^{2}{ }^{(}$, Shimaa Husien ${ }^{1}\left(\mathbb{D}\right.$, Tarek Youssef ${ }^{3}$, Ehab Azab ${ }^{4} \mathbb{D}$, \\ Adil A. Gobouri ${ }^{5}$ and Gehan Safwat ${ }^{3}$ \\ 1 Egyptian Petroleum Research Institute (EPRI), Nasr City, Cairo 11727, Egypt; shimahessin@yahoo.com \\ 2 National Research Centre (NRC), Polymers \& Pigments Department, 33 El-Buhouth St. Dokki, \\ Cairo 12622, Egypt; ae.abdel-hamid@nrc.sci.eg \\ 3 Faculty of Biotechnology, October University for Modern Sciences \& Arts (MSA University), \\ 6th October City 12451, Egypt; tarek.youssef@msa.edu.eg (T.Y.); gsafwat@msa.edu.eg (G.S.) \\ 4 Department of Biotechnology, College of Science, Taif University, P.O. Box 11099, Taif 21944, Saudi Arabia; \\ e.azab@tu.edu.sa \\ 5 Department of Chemistry, College of Science, Taif University, P.O. Box 11099, Taif 21944, Saudi Arabia; \\ a.gobouri@tu.edu.sa \\ * Correspondence: a.labena@epri.sci.eg
}

check for updates

Citation: Labena, A.; Abdelhamid, A.E.; Husien, S.; Youssef, T.; Azab, E.; Gobouri, A.A.; Safwat, G. Grafting of Acrylic Membrane Prepared from Fibers Waste for Dyes Removal: Methylene Blue and Congo Red. Separations 2021, 8, 42. https:// doi.org/10.3390/separations 8040042

Academic Editor: Cristina Maria Martins Almeida

Received: 27 January 2021

Accepted: 25 March 2021

Published: 1 April 2021

Publisher's Note: MDPI stays neutral with regard to jurisdictional claims in published maps and institutional affiliations.

Copyright: (c) 2021 by the authors. Licensee MDPI, Basel, Switzerland. This article is an open access article distributed under the terms and conditions of the Creative Commons Attribution (CC BY) license (https:/ / creativecommons.org/licenses/by/ $4.0 /)$.

\begin{abstract}
Dyes are a type of pollutant that have been discharged into water streams by various industries and had harmful effects on the environment and human health. Therefore, present work was directed to recycle acrylic fibers waste to be used as an adsorbent to exclude dyes such as methylene blue (MB) and Congo red (CR) from dyes-polluted wastewater. Acrylic fibers waste was converted into membrane followed by chemical grafting with $p$-phenylenediamine monomer to form functional modified membranes. Afterwards, some characterization analyses; Fourier transforminfrared, scanning electron microscope, swelling behavior, and porosity properties were performed for the acrylic fiber grafted membrane (AFGM). For obtaining the best conditions that permit the highest adsorption capacity of the AFGM, some preliminary experiments followed by general full factorial design experiments were displayed. Langmuir, Freundlich isotherms and kinetic studies evaluations were applied. Results revealed that, the adsorption capacities of the AFGM were $61 \%$ for Methylene blue and $86 \%$ for Congo red that stated the high affinity of the AFGM to the anionic dyes. The reusability of the AFGM membranes in different cycles for 3Rs processes "Removal, Recovery, and Re-use" indicated the efficiency of the AFGM to be used in wastewater treatment.
\end{abstract}

Keywords: adsorption; acrylic fibers; dyes; grafting; membrane; phenylenediamine wastewater

\section{Introduction}

Dyes are a valuable class of organic synthetic compounds that were used in many industries, particularly textiles as a coloring agent. Therefore, dyes have become one of the common pollutants to environment and water stream, either during their synthesis process or during the textile dyeing process [1]. Discharging of dyes-contaminated effluents into water flow had a harmful effect on the environment even at a small residue of dye due to their highly visible colors even at low dye concentration. Dyes are toxic and non-degradable compounds and when release into the natural sources of water they prevent the light-penetration into the aquatic plants and further disturb their photosynthesis process [2]. Furthermore, they had wide negative effects on human health where they cause dermatitis, allergies, skin irritation, cancers, reproductive and kidneys system damaging [3,4]. Hence, many conventional and non-conventional treatments approaches were developed for dyes removal from contaminated wastewater [5-9]. Dyes are normally not easily treated using conventional wastewater-treatment methods due to their inhibitory and recalcitrant nature [10-14]. Most of dyes are synthetic and has an aromatic complex 
molecular structure, and these make them more stable and non-biodegradable [15]. These were why non-conventional, safe, economically, and eco-friendly dyes removal-approaches "adsorption" was suggested by a lot of researchers, lately. Adsorption is a non-conventional method by which dyes may adsorb on the surface of the adsorbent material [16-18]. For instance, adsorption by natural polymeric substances is one of the most promising nonconventional approach and applicable methods for pollutants removal from contaminated wastewater $[19,20]$. This property may be attributed to their potentiality to have different shapes, simple processing, and easy regeneration [21-23]. Electro-spun nanofibrous polyimides with ion exchange performance were prepared as adsorptive membranes for the treatment of dye-loaded textile wastewater [24,25]. One of the most fibers forming polymers used in textile production is acrylic polymers (acrylic fibers) due to their versatile properties. The acrylic fibers consist mainly of nearly $85-90 \%$ acrylonitrile, whereas the residual is another acrylic monomer such as acrylic ester or acid that were added during the synthesis process of acrylic fibers in order to enhance certain property for example dyeability or processing [26]. Acrylic fiber wastes produced by textile industry may cause environmental problems. Therefore, many researchers tried to reuse the fiber waste as in concrete and soil enforcement and in adsorption process but after chemical treatment [27-29]. Wang et al. functionalized polyacrylonitrile fibers (PANF-g-CDs) with amine rich carbon dots via the hydrothermal method and used them to remove anionic dyes from wastewater. The PANF-g-CDs showed high adsorption capacity (422 mg/g) for methyl orange [30]. Therefore, the ongoing study aimed to use a synthetic polymeric membrane obtained from acrylic fibers waste to formulate an acrylic membrane. After that, chemical grafting polymerization of $p$-phenylenediamine was performed in order to form functional modified membranes. The morphology and the functional groups of AFGM were evaluated by scanning electron microscope (SEM), and Fourier transform infrared (FT-IR). Together with the porosity, swelling and adsorption assays, they allowed the characterization of AFGM. The AFGM was used for methylene blue (MB) and Congo red (CR) removal from polluted synthetic wastewater using static model. "However, most adsorption studies were used the shaking model to obtain the highest pollutant removal efficiency. A static model was applied to reduce the adsorption costs for an easily industrial application." Furthermore, the optimization process was performed for the membrane to get the highest MB and CR removal capacity, such optimization as studying one factor's effect while keeping all other parameters constant [26]. Such optimization experiments were followed by general full factorial design experiment by studying more than one factor at the same time [20]. Langmuir, Freundlich and kinetic studies were applied for the AFGM. Additionally, the AFGM was studied for recovery and reuse application to achieve at the end a product with 3Rs applications (removal, recovery and reuse).

\section{Materials and Methods}

\subsection{Materials}

Acrylic fibers waste was collected from local textile company; these fibers were synthetic fibers made from at least $85 \%$ acrylonitrile monomer and the residual other acrylic monomer mainly vinyl acetate or methyl acrylate. Polyethylene glycol (PEG) molecular weight 600 was purchased from Aldrich. Methylene blue as cationic dye and Congo red as anionic dye were supplied from Merck. Dimethylformamide was supplied from Sigma Aldrich. All used chemicals are of purity higher than $99 \%$. $\mathrm{NaOH}$ and $\mathrm{HCl}$ were of analytical grade, and they were supplied from El-Nasr Company Egypt.

\subsection{Membrane Preparation}

Acrylic fibers waste conversion to membranes were employed by applying a phase inversion technique [31,32]. At first, acrylic fibers waste (1.7 g) was dissolved in $(9 \mathrm{~mL})$ dimethyl formaldehyde (DMF) in a conical flask at $60{ }^{\circ} \mathrm{C}$ under magnetic stirring until complete dissolution. Afterwards, polyethylene glycol (PEG) with 5\% respect to the polymer was added to the solution as a pore former to improve the membrane porosity. 
Afterword, the solution was poured and casted on a clean dried glass plate by using a casting knife of $250 \mu \mathrm{m}$ thickness. The glass plate which contains the casted solution was immersed in coagulated water bath without any evaporation process, for at least $1 \mathrm{~h}$. After that, the membrane was removed, rinsed with water and air dried.

\subsection{Membrane Grafting}

After membrane preparation, it was grafted with $p$-phenylenediamine via oxidative polymerization technique [33]. The membrane was immersed in a solution of $p$ phenylenediamine that was dissolved in $1 \mathrm{M} \mathrm{HCl}$ and left for $1 \mathrm{~h}$ to allow the monomer to penetrate within the membrane. Afterwards, ammonium persulfate (equal molar ratio $p$-phenylenediamine) was dissolved in $1 \mathrm{M} \mathrm{HCl}$ and added slowly to the solution under mild shaking then left for a night at room temperature. The solution and the membrane became dark black, which indicated the formation of the AFGM chains and formation of poly-phenylenediamine. The membranes were removed and washed several times with distilled water until the rinse water become clear and the $\mathrm{pH}$ present neutrality. The membranes weight was recorded before and after grafting and the grafting percentage was calculated by applying Equation (1):

$$
\text { Grafting }(\%)=\frac{(W g-W 0)}{W 0} \times 100
$$

where, $\mathrm{Wg}$ is the dry membrane polymer weight after grafting, and $W 0$ is membrane polymer weigh before grafting (zero (0) time).

\subsection{Dyes Preparation}

Methylene blue (MB) (C16H18ClN3S; $319.85 \mathrm{~g} / \mathrm{mol})$ and Congo red (CR) $\left(\mathrm{C}_{32} \mathrm{H}_{22} \mathrm{~N}_{6}\right.$ $\mathrm{Na}_{2} \mathrm{O}_{6} \mathrm{~S}_{2} ; 696.665 \mathrm{~g} / \mathrm{mol}$ ) dyes were used for adsorption experiments. A stock solution of $1000 \mathrm{mg} / \mathrm{L}$ of MB and CR dyes were prepared by dissolving $1 \mathrm{~g}$ from each dry powder dye into $1 \mathrm{~L}$ of distilled water. After that, serial dilutions were applied to prepare the desired concentration throughout this study.

\subsection{Charcterzation of AFGM}

\subsubsection{Scanning Electron Microscope (SEM)}

The morphology of the AFGM surface was characterized using scanning electron microscopy (SEM) of high resolution (QUANTA FEG 250, ESEM, operated with an accelerating voltage of $200-30 \mathrm{kV}$ and an operating voltage of 5-30 kV). Regarding to the examination, the membranes were sputter-coated by gold where S150A Sputter CoaterEdwards were used.

\subsubsection{Fourier Transform Infrared (FT-IR)}

Dried membrane's material after and before grafting were evaluated using FT-IR Spectroscopy to detect the membranes functional groups by using a wavelength range from $400-4000 \mathrm{~cm}^{-1}$.

\subsubsection{Porosity}

The membrane porosity was estimated using dry-wet-weight method [24,25,34,35]. The membrane samples $(3 \mathrm{~cm} \times 3 \mathrm{~cm})$ were weighted dry (Wdry) and immersed in distilled water for a day. The wet-weight (Wwet) was assessed after removing the excess water using filter paper. The membrane porosity was calculated by the Equation (2):

$$
\varepsilon(\%)=[\text { Wwet }- \text { Wdry dwAh }] \times 100
$$

where $\varepsilon$ refers to the membrane porosity, dw refers to the density of pure water $\left(0.998 \mathrm{~g} / \mathrm{cm}^{3}\right)$, A refers to the membrane area in the wet state $\left(\mathrm{cm}^{2}\right)$ and $\mathrm{h}$ refers to the membrane thickness in the wet state $(\mathrm{cm})$. 


\subsubsection{Swelling}

The AFGM swelling property was evaluated by immersing the membrane samples $\left(3 \times 3 \mathrm{~cm}^{2}\right)$ into $250 \mathrm{~mL}$ distilled water at a room temperature $\left( \pm 20^{\circ} \mathrm{C}\right)$ in atmospheric conditions until swelling equilibrium was obtained [36]. The assay was performed in triplicate. Afterwards, the AFGM was removed from the water and dried with filter paper and weighed. Additionally, the swelling capacity was calculated by the Equation (3):

$$
\operatorname{Swelling}(\%)=\frac{W_{2}-W_{1}}{W_{1}} \times 100
$$

where $W_{1}(\mathrm{~g})$ and $W_{2}(\mathrm{~g})$ indicate the weights of the dried and swollen membranes, respectively.

\subsection{Adsorption and Optimization Experiments}

A weighted amount of the AFGM was added to the dyes polluted solution. The dyes concentration was quantified before and after the treatment with a UV-Visible spectrophotometer (Cary $100 \mathrm{UV}-\mathrm{Vis}$ ) at $668 \mathrm{~nm}$ and $497 \mathrm{~nm}$ for MB and CR, respectively. The removal efficiency of $\mathrm{MB}$ and $\mathrm{CR}$ was estimated by the Equation (4):

$$
\text { Removal effeciency }(\%)=\frac{C_{o}-C_{e}}{C_{o}} \times 100
$$

where $C_{\mathrm{o}}$ represented the initial dye concentration and $C_{e}$ represented the final concentration.

The adsorption capacity $(Q e)$ was calculated by the Equation (5)

$$
\text { Adsorption capacity }\left(\mathrm{Qe}\left(\frac{\mathrm{mg}}{\mathrm{g}}\right)\right)=\frac{\mathrm{Co}-\mathrm{Ce}}{m} \times V
$$

where $C_{o}$ represented the initial dye concentration and $C_{e}$ represented the final concentration. $V$ is the volume of the solution (l) and $m$ is the mass of adsorbent employed (g).

Different parameters were optimized through the preliminary optimization by onefactor-at-a-time (OFAT). The optimization of adsorption process was processed by studying the effect of different time intervals " $0.5,1,3,6,10,15^{\prime \prime} \mathrm{h}$, different $\mathrm{pH}$ " $3,5,7$ " and different dye concentrations " $50,100,150$, and $200 \mathrm{mg} / \mathrm{L}$ ". Three replicates by parameter were performed. Its standard deviation is express with error bars in respective figures. The adsorption procedure evaluated by the full factorial experimental allowed to define the optimum parameters to obtain the highest removal efficiencies for MB and CR and tested as follows.

\subsection{Full Factorial Design}

Full factorial design experiment was displayed according to the selected low and high levels of the factors that were determined by the OFAT and displayed in Table 1. The matrix of the factorial design and the measured $\mathrm{MB}$ and $\mathrm{CR}$ removal efficiencies were shown in Table 2 with fits and residuals values. After that, the results were demonstrated with the Minitab@18 software and the resulted plots were displayed and interpreted [37].

\begin{tabular}{|c|c|c|c|c|}
\hline \multirow{2}{*}{ Factor } & \multirow{2}{*}{ Symbol } & \multirow{2}{*}{ Statistical Code } & \multicolumn{2}{|c|}{ Values of Coded Levels } \\
\hline & & & (Low) -1 & (High)+1 \\
\hline Time & Time (h) & A & 3 & 15 \\
\hline $\begin{array}{c}\text { Dyes } \\
\text { Concentration }\end{array}$ & Conc. (mg/L) & $\mathrm{D}$ & 50 & 200 \\
\hline Pollutant & Pollutant & C & MB & $\mathrm{CR}$ \\
\hline
\end{tabular}

Table 1. Coded low and high levels of the factors that were used in full factorial optimization model of methylene blue and Congo red adsorption by the AFGM. 
Table 2. Design of matrix of methylene blue and Congo red adsorption by using the AFGM, $n=1$.

\begin{tabular}{cccccccccc}
\hline $\begin{array}{c}\text { Std } \\
\text { Order }\end{array}$ & $\begin{array}{c}\text { Run } \\
\text { Order }\end{array}$ & Pt Type & Blocks & Time (h) & $\begin{array}{c}\text { Conc. } \\
(\mathbf{m g} / \mathbf{L})\end{array}$ & Pollutant & RE (\%) * & FITS ** & RES *** \\
\hline 6 & 1 & 1 & 1 & 15 & 50 & CR & 86.00 & 92.69 & -6.693 \\
4 & 2 & 1 & 1 & 3 & 200 & CR & 20.35 & 26.13 & -5.78 \\
7 & 3 & 1 & 1 & 15 & 200 & MB & 23.25 & 28.18 & -4.931 \\
1 & 4 & 1 & 1 & 3 & 50 & MB & 43.20 & 47.21 & -4.018 \\
5 & 5 & 1 & 1 & 15 & 50 & MB & 61.00 & 56.06 & 4.931 \\
2 & 6 & 1 & 1 & 3 & 50 & CR & 59.80 & 54.01 \\
3 & 7 & 1 & 1 & 3 & 200 & MB & 23.35 & 19.33 & 4.018 \\
8 & 8 & 1 & 1 & 15 & 200 & CR & 71.50 & 64.80 \\
\hline
\end{tabular}

${ }^{*}$ RE, removal efficiency; ${ }^{* *}$ FITS, the value of point estimates of the mean RE for given values of the factors; ${ }^{* *}$ RES, residuals (difference between observed value and its corresponding fitted value).

\subsection{Langmuir and Freundlich Isotherms}

Langmuir and Freundlich isotherms were used to determine the MB and the CR adsorption mechanism by the AFGM. Linear form of Langmuir and Freundlich isotherms were applied as follows:

\subsubsection{Langmuir Isotherm}

Maximum adsorption capacity of the AFGM towards MB and the CR were studied by applying Equation (6) [38]:

$$
\frac{C e}{Q e}=\frac{C e}{Q \max }+\frac{1}{b Q \max }
$$

where $b$ represents a constant related to the AFGM adsorption/desorption capacity, and $Q_{\max }$ is the maximum adsorption capacity of the AFGM upon complete saturation of its surface, $C_{e}(\mathrm{mg} / \mathrm{L})$ is the dye concentration at equilibrium and $Q_{e}(\mathrm{mg} / \mathrm{g})$ is the adsorption capacity at equilibrium.

\subsubsection{Freundlich Isotherm}

Freundlich isotherm is an empirical equation employed to estimate the adsorption capacity of AFGM to MB and CR dyes, and it was represented by the Equation $(7)[28,39]$ :

$$
\log Q e=\log K f+\frac{1}{n} \log C e
$$

where $Q e$ is the quantity of solute adsorbed at equilibrium (adsorption density: mg of MB or CR per $\mathrm{g}$ of $\mathrm{AFGM);C} e$ is the concentration of $\mathrm{MB}$ and $\mathrm{CR}$ dyes in solution at equilibrium $(\mathrm{mg} / \mathrm{L})$; and $K F$ and $1 / n$ are empirical constants dependent on the nature of sorbent and sorbate and the temperature.

\subsection{Kinetics Studies}

Adsorption process kinetics was performed to determine the $\mathrm{MB}$ and $\mathrm{CR}$ adsorption rate towards the AFGM that controls equilibrium time.

\subsubsection{Pseudo First-Order Model}

The pseudo first-order model was performed according to Equation (8):

$$
\ln (Q e-q Q t)=\log Q e-\frac{K 1}{2.303}
$$

where $Q e(\mathrm{mg} / \mathrm{g})$, is adsorbed $\mathrm{MB}$ and $\mathrm{CR}$ dyes at equilibrium per unit weight of AFGM $q t$ $(\mathrm{mg} / \mathrm{g})$ is adsorbed $\mathrm{MB}$ and $\mathrm{CR}$ at time $t$, and $k 1$ is the rate constant per minute.

A plot of $\ln (Q e-Q t)$ versus time $(t)$ indicates a straight line of slope $(k 1 / 2.303)$ and an intercept of $\log (Q e)$. 


\subsubsection{Pseudo Second-Order Model}

The data was analyzed by the pseudo second-order Equation (9):

$$
\frac{t}{Q_{t}}=\frac{1}{K_{2} Q_{e}{ }^{2}}+\frac{t}{Q_{e}}
$$

where $K_{2}$ expresses the equilibrium rate constant $(\mathrm{g} / \mathrm{mg} \mathrm{min})$, and $Q_{e}$ and $Q_{t}$ express the sorption capacities at equilibrium and at time $(t)$, respectively. A plot $t / Q_{t}$ versus $t$ shows a straight line of slope $\left(1 / Q_{e}\right)$ and an intercept of $\left(1 / K_{2 Q e^{2}}{ }^{2}\right.$.

\section{Results}

\subsection{Acrylic-Fiber Grafted Membrane (AFGM) Characterization}

\subsubsection{SEM}

Figure 1a displayed the blank membrane surface topography at different magnifications, the membrane had porous structure with the appearance of small fiber like structure, which might be due to fiber additives or insufficient dissolution time. Figure $1 \mathrm{~b}$, the membrane surface, indicated the high porosity of the membrane which resemble the sponge like structure. The surface of the AFGM appeared as multilayers with larger pore size than the blank membrane. The result also displayed disappearance of the small tiny fibers, which indicated complete coverage of the grafted layer over the membrane surface. Figure $1 \mathrm{c}, \mathrm{d}$ displayed a blank acrylic membrane cross section and the AFGM, respectively. The figure revealed that, the cross-section of the membrane had macro-voids structure with many large pores that indicated the spontaneous solvent nonsolvent de-mixing during the membrane immersion onto the coagulation bath, which was known in phase inversion technique. The cross section of the AFGM had a similar structure with no obvious grafts at these magnifications, which may indicate the low grafting percentage occurred in bulk of the membrane. Whereas Figure 1e exhibited the bottom surface of the acrylic membrane (facing the glass plate during the membrane preparation) which appeared highly arranged porous structure with larger pore size than the top surface (facing the water during the manufacturing).

\subsubsection{FT-IR}

The blank acrylic membrane represented a distinct peak at $2241 \mathrm{~cm}^{-1}$, which belongs to nitrile group (CN) [29] and the peak at $1736 \mathrm{~cm}^{-1}$ corresponding to carbonyl group $\mathrm{C}=\mathrm{O}$ of acrylic additives of acrylonitrile fiber. The acrylic fiber contains nearly $85 \%$ of acrylonitrile and the rest of the percent is another acrylate monomer. The band appeared at $2922 \mathrm{~cm}^{-1}$ and $2888 \mathrm{~cm}^{-1}$ related to stretching of $\mathrm{CH}$ and $\mathrm{CH}_{2}$, respectively [8]. Whereas $1452 \mathrm{~cm}^{-1}$ and $1378 \mathrm{~cm}^{-1}$ peaks corresponding to $\mathrm{CH}_{2}$ and $\mathrm{CH}$ bending, the peak at $1234 \mathrm{~cm}^{-1}$ related to stretching of C-O.

After grafting of the acrylic membrane, the peak at 2241 reduced and shifted to $2236 \mathrm{~cm}^{-1}$ also carbonyl band at $1736 \mathrm{~cm}^{-1}$ was shortened and shifted to $1733 \mathrm{~cm}^{-1}$. The appearance of peaks at 1540 and $1600 \mathrm{~cm}^{-1}$ corresponding to aromatic benzene ring $\mathrm{C}=\mathrm{C}$. from these data the grafting process was successfully occurred onto the acrylic membrane, see Figure 2. 

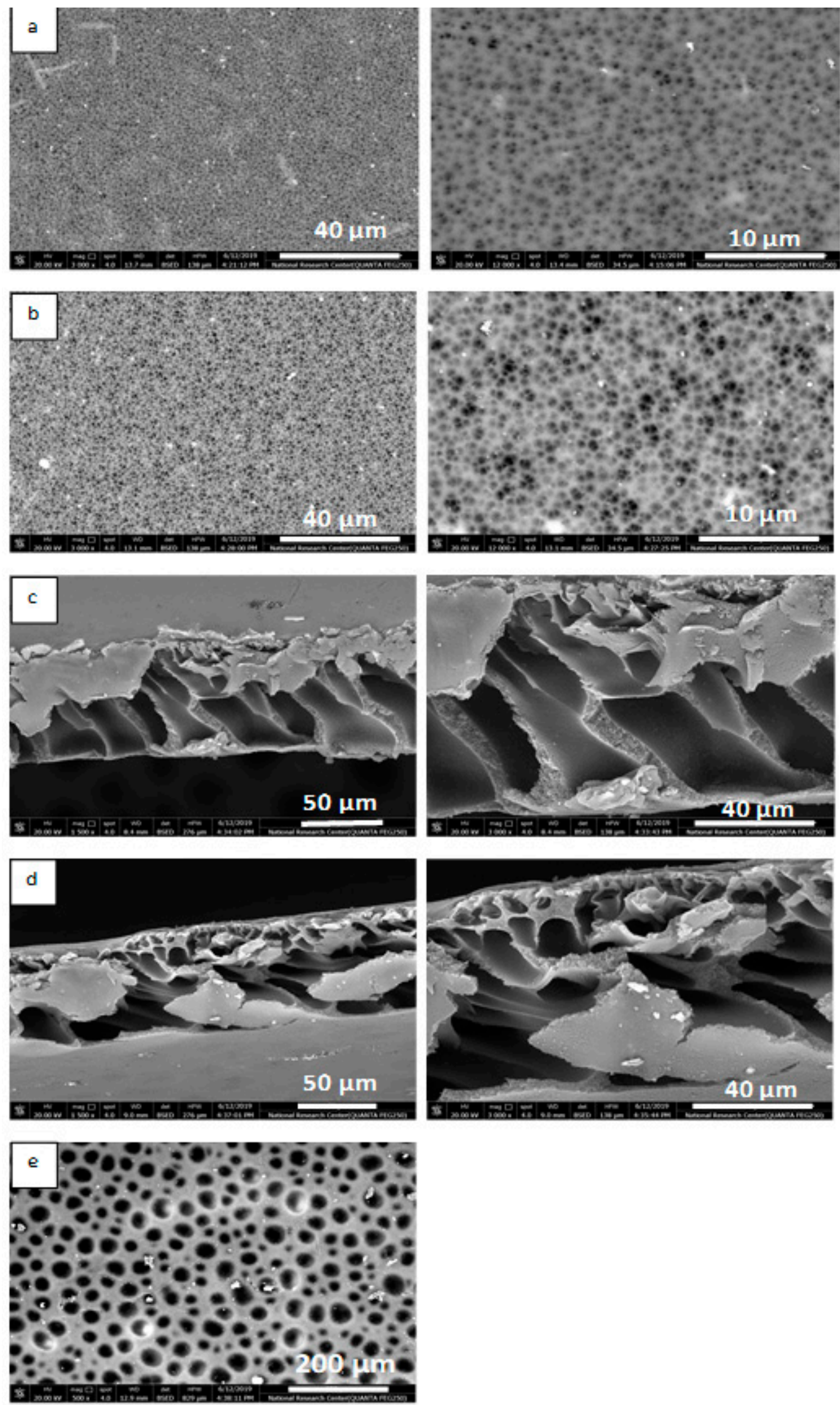

Figure 1. SEM analysis of membrane for (a) blank membrane surface, (b) AFGM surface, (c) cross section of blank, (d) cross section of the AFGM at different magnification (left and right) (e) bottom surface of blank membrane. 


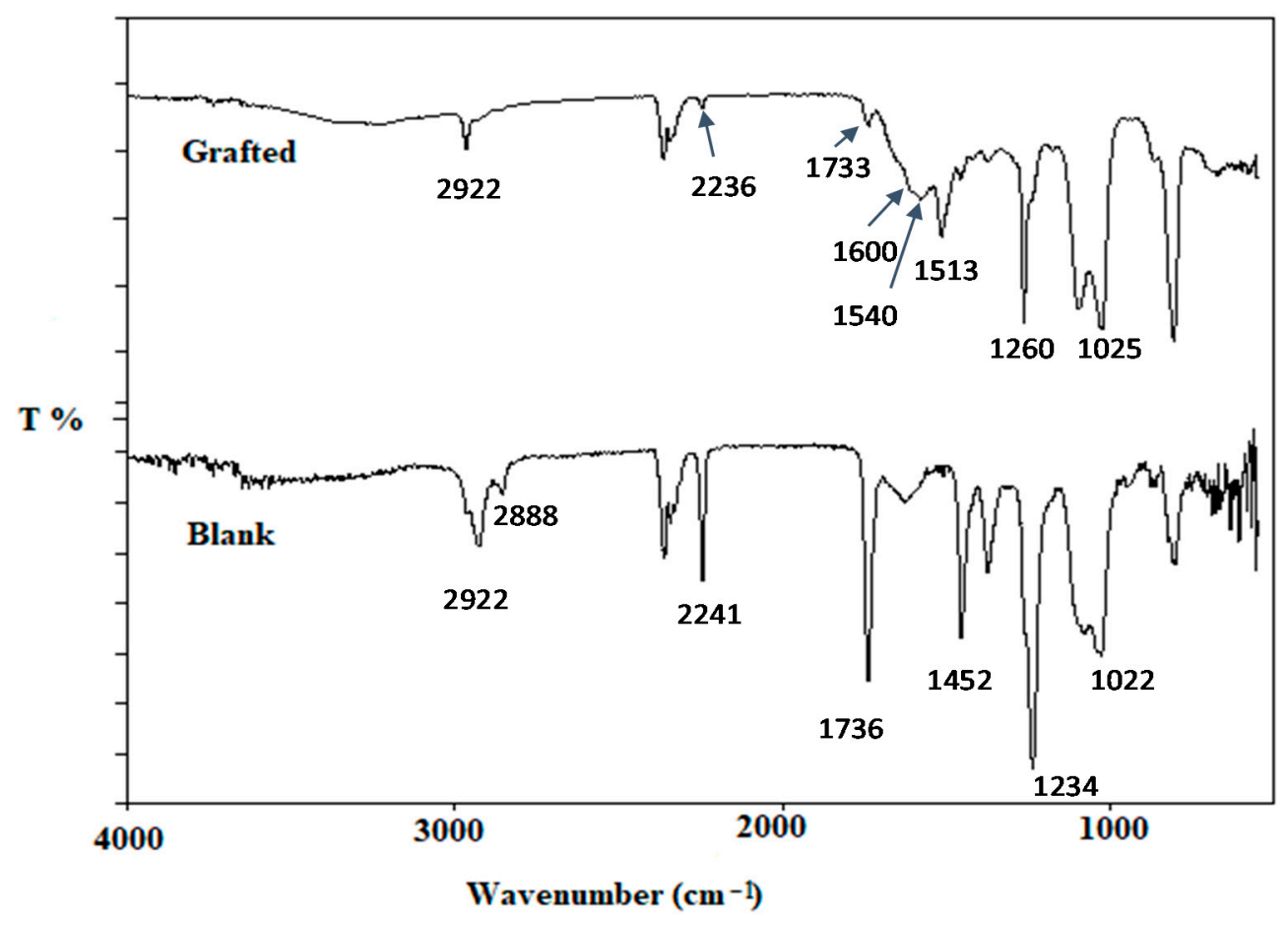

Figure 2. FT-IR analysis of the acrylic membrane before and after grafting.

\subsubsection{Grafting Percentage}

The membrane grafting percentage was reported in Table 3 . The result referred to the weight gain after grafting process by $14.4 \%$ from its original weight. This demonstrates that the grafting process not just surface grafting but also bulk grafting. The increased in weight was not so much but it occurred on both surface and inside the membrane. This result expressed the successful grafting of poly $p$-phenylenediamine using ammonium persulfate as an initiator at a mild condition.

Table 3. Porosity, swelling measurements and grafting percent for acrylic membrane and the AFGM.

\begin{tabular}{cccc}
\hline Membrane & Porosity (\%) & Swelling (\%) & Grafting (\%) \\
\hline $\begin{array}{c}\text { Blank acrylic membrane } \\
\text { Acrylic fiber grafted } \\
\text { membrane (AFGM) }\end{array}$ & 23.1 & $420 \%$ & - \\
\hline
\end{tabular}

\subsubsection{Porosity}

Table 3 showed the porosity of the membranes. The blank membrane recorded about $23.1 \%$ of the polymer membrane's weight, while it recorded $15 \%$ for the AFGM. A possible explanation for this largely decreased is the penetration of new polymer within the pores in AFGM, which reduced the voids in the membrane and declined its porosity. The grafted layer on the membrane surface formed on the porous substrate had the same morphology as the base substrate, so it appeared as porous in the SEM testing.

\subsubsection{Swelling}

Swelling of the acrylic membrane before and after grafting was presented in Table 3. It was noticed that the swelling performance of the membrane decreased from 420 to $354 \%$ indicating the formation of the AFGM polymer within the membrane voids and pores, not only on the membrane surface. The decline in the swelling ratio may also be due to the hydrophobic nature of the AFGM (poly p-phenylenediamine) with the aromatic structure. These data and the change in porosity and swelling confirmed the construction of the grafting branches within the AFGM. 


\subsection{Adsorption and Optimization Experiments Results}

\subsubsection{Effect of Contact Time}

During $15 \mathrm{~h}$, the adsorption capacity of AFGMs for MB and CR dyes were evaluated (Figure 3). The contact time was directly proportional to the percentage of the AFGM adsorption capacity for both $\mathrm{MB}$ and $\mathrm{CR}$ dyes. The $\mathrm{CR}$ removal recorded higher adsorption capacity than MB within the time progress, which stated the affinity of the AFGM with cationic amine groups towards the anionic dyestuff. The time was high due to a static model used; however, previous studies exhibited a long time up to 1500 min (nearly $24 \mathrm{~h}$ ) even using a $150 \mathrm{rpm}$ shaking model $[40,41]$.

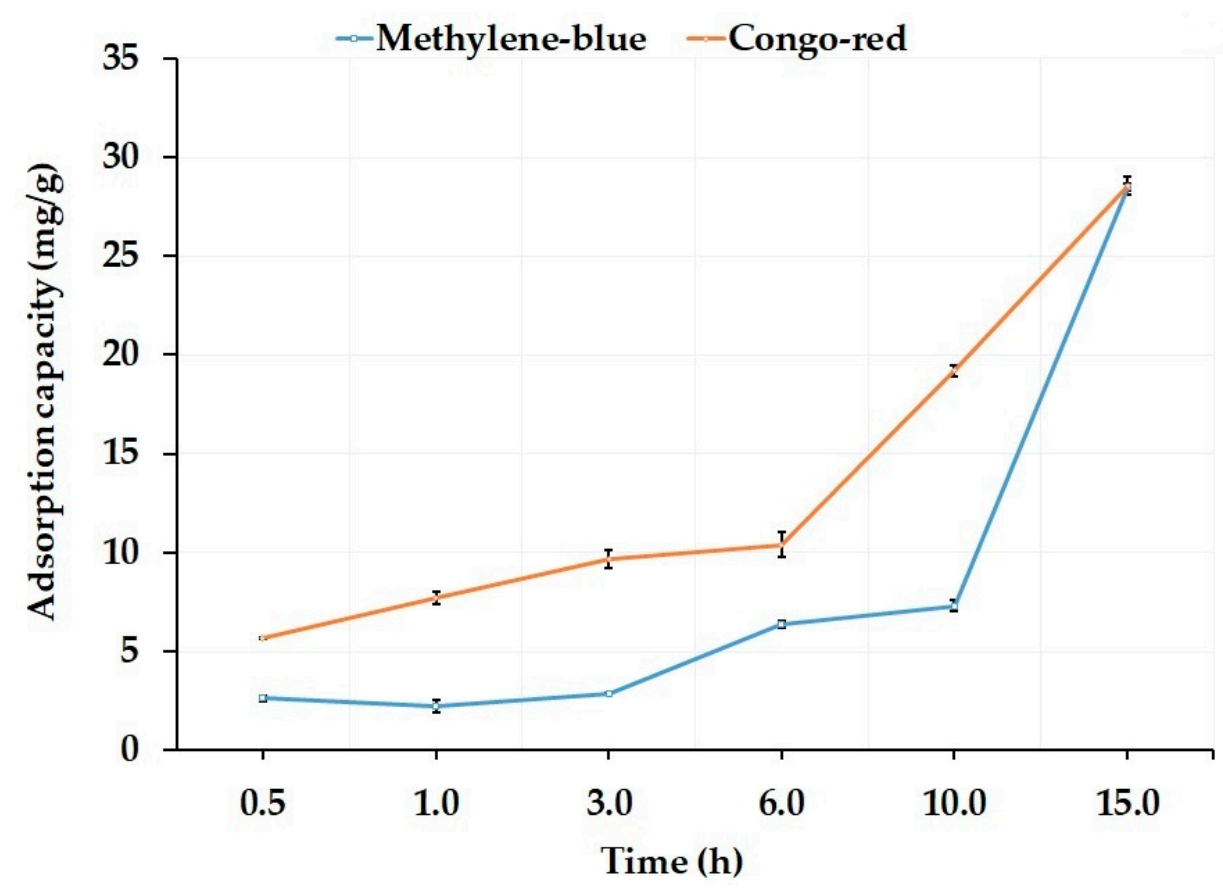

Figure 3. Effect of time on removal efficiency of Methylene blue and Congo red dyes by the AFGM: adsorption capacity vs. time, $n=3$.

\subsubsection{Effect of $\mathrm{pH}$}

The highest adsorption capacity for both dyes were accomplished at pH 5, while at higher acidic levels adsorption capacity tends to dramatically decrease for the MB which the cationic protons induce a competition between cationic MB molecules. Additionally, it was observed that, $\mathrm{CR}$ was turned onto violet then blue color and afterwards precipitated at acidic condition around $\mathrm{pH} 3$ and no-result was recorded at this $\mathrm{pH}$ for $\mathrm{CR}$ removal and adsorption capacity see Figure 4 . This observation was due to; at relatively high concentration of CR at acidic condition the hydrophobic interaction between the aromatic rings of the dye molecules was promote, which occur by the $\pi-\pi$ stacking phenomenon resulted in agglomeration and precipitation of this dye at these condition [42,43].

\subsubsection{Effect of Concentration}

Results demonstrated that, the increase in the initial dye-concentration leads to an increase in the AFGM adsorption capacity for both dyes. The highest adsorption capacities were recorded between 40 to $50 \mathrm{mg} / \mathrm{g}$ for both $\mathrm{MB}$ and CR, respectively see Figure 5 . The AFGM showed adsorption capacities of 43 and $48 \mathrm{mg} / \mathrm{g}$ for dyes at high concentration of $200 \mathrm{mg} / \mathrm{L}$ for MB and CR, respectively. The results showed that, the adsorption of anionic dye was higher for the cationic one due to the cationic nature of the prepared adsorbent. However, the adsorption capacities were decreased by increasing concentration from 50 , 100, 150, to $200 \mathrm{mg} / \mathrm{L}$ and this result was stated in previous studies [44-47]. At a diluted concentration; the adsorption capacities were higher due to the removal of most of dye 
molecules. However, at high dye concentrations the adsorption capacities were decreased with increasing in adsorbent capacity due to the higher diffusion of the dye molecules within the polymer matrix and pores.

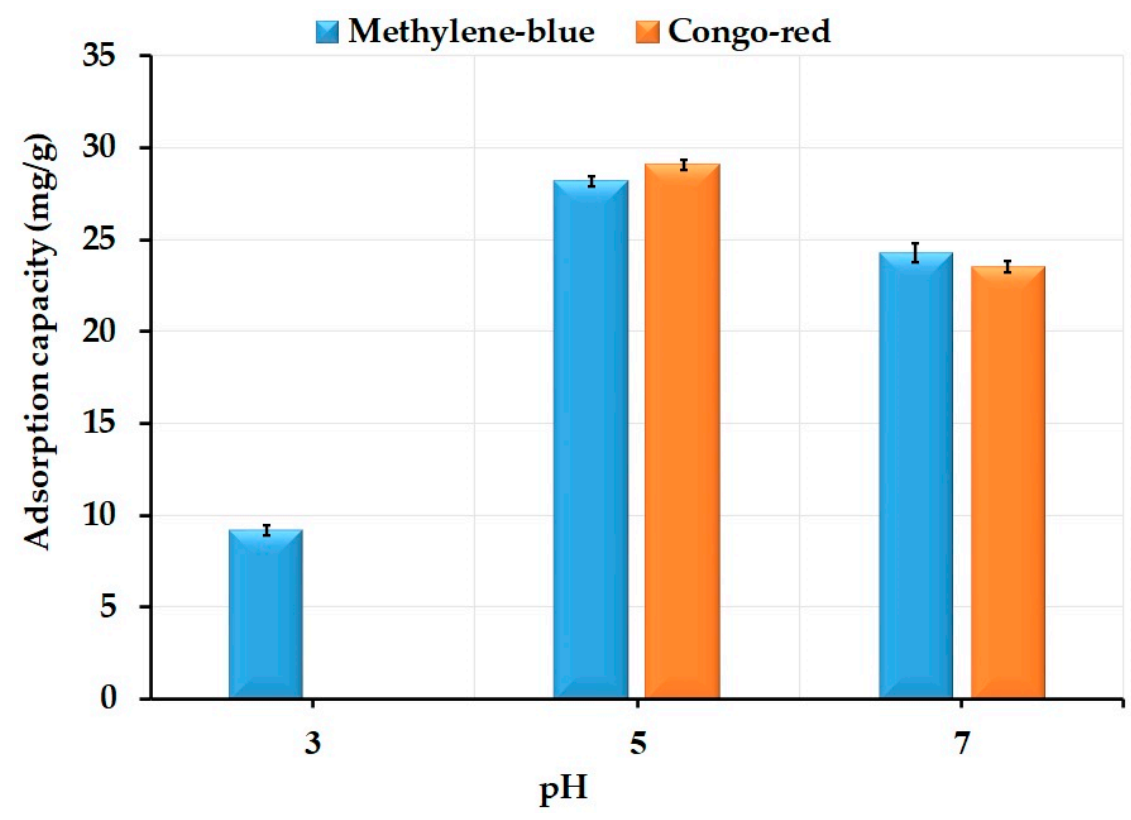

Figure 4. Effect of $\mathrm{pH}$ on removal efficiency of Methylene blue and Congo red dyes by the AFGM: adsorption capacity vs. time, $n=3$.

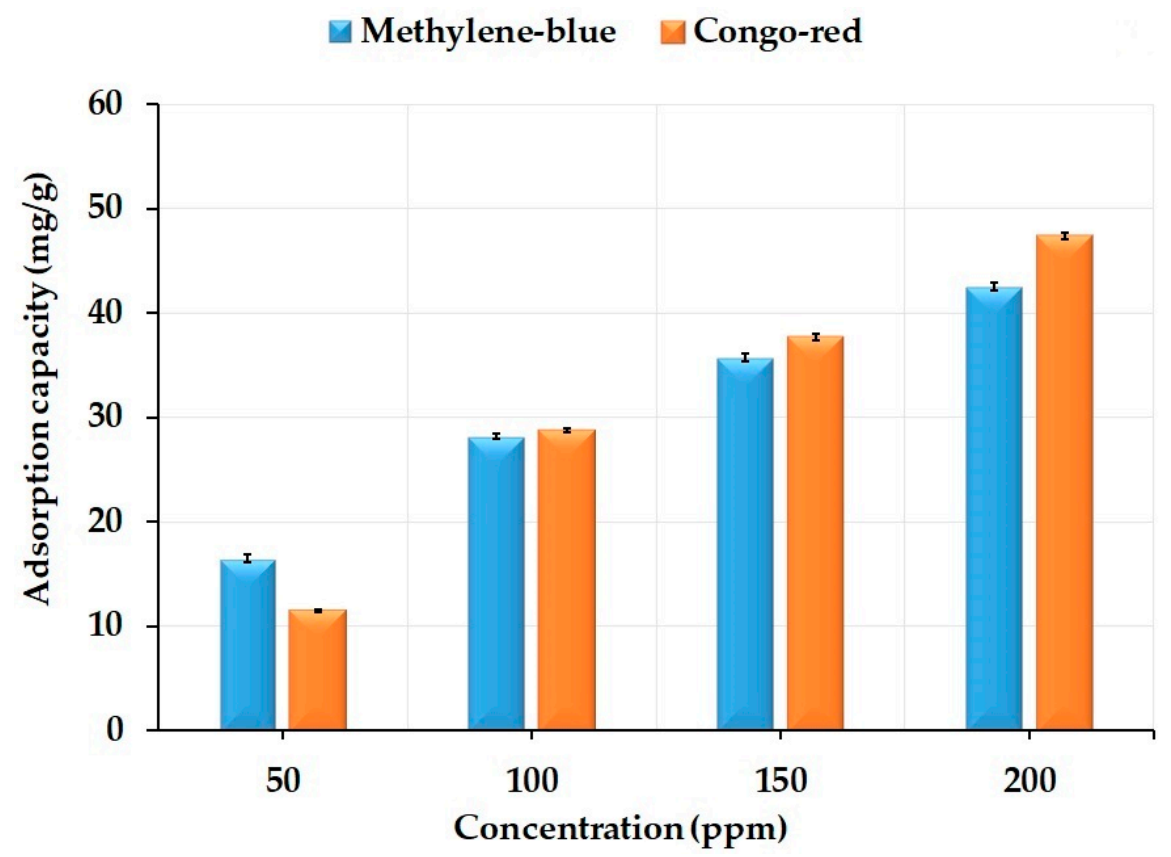

Figure 5. Effect AFGM adsorption capacity to methylene blue and Congo red dyes based on their concentration, $n=3$.

\subsubsection{Factorial Design}

The Main Effects

Figure 6 showed the main effects plot which represented the deviation of the average from the low to the high level of each factor and its effect on the dye's removal percent [44]. The increase in deviation from the low to the high levels of the factor reflected the factor 
positive effect on the dye's removal efficiency that represent the increase in the removal efficiency. In contrast, the reduction that appear from the high to the low level of the factor reflect the negative affect of this factor on the dye's removal efficiency. According to this information, Figure 6 and Table 4 stated that, both time and pollutant type positively affected the $\mathrm{MB}$ and $\mathrm{CR}$ removal percent, whereas dyes concentration negatively affected the removal efficiency. Furthermore, levels $15 \mathrm{~h}$ contact time in static mode and $50 \mathrm{ppm}$ were the optimum levels that give the highest dyes removal. Additionally, it was noticed that the CR removal by the AFGM was better than MB removal.

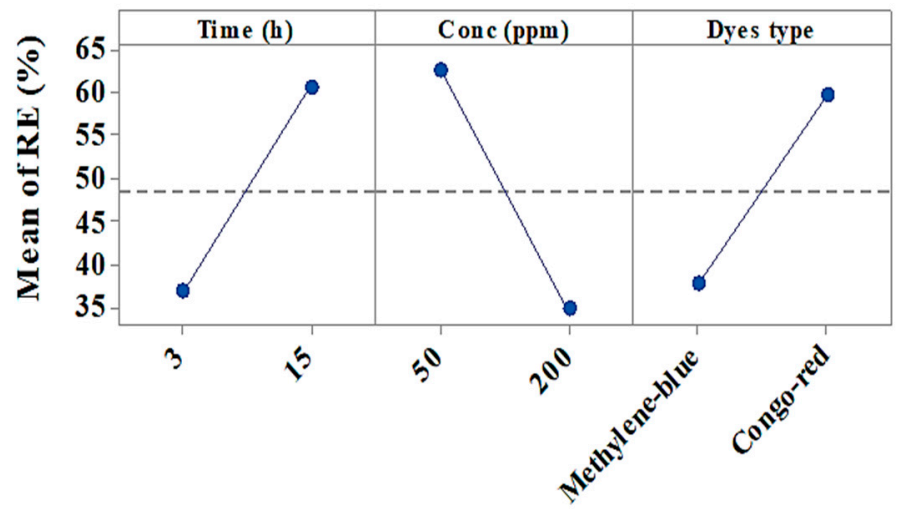

Figure 6. The effect of the main parameters on the removal efficiency of methylene blue and Congo red dyes by the AFGM.

Table 4. Coded co-efficient factors of methylene blue and Congo red dyes adsorption by AFGM.

\begin{tabular}{cccccc}
\hline Term & Effect & Coef & SE Coef & T-Value & $p$ Value \\
\hline Constant & & 48.56 & 3.15 & 15.44 & 0.001 \\
Time $(\mathrm{h})$ & 23.76 & 11.88 & 3.15 & 3.78 & 0.032 \\
Conc. $(\mathrm{mg} / \mathrm{L})$ & -27.89 & -13.94 & 3.15 & -4.43 & 0.021 \\
Pollutant & 21.71 & 10.86 & 3.15 & 3.45 & 0.041 \\
Time (h)*Pollutant & 14.91 & 7.46 & 3.15 & 2.37 & 0.098 \\
\hline
\end{tabular}

The Interaction Effects

The interaction effects are the studying of two-interacted factors that had an effect on the removal efficiency [48]. Figure 7 and Table 4 illustrated that, the interaction effects of the optimized factors to obtain the highest $\mathrm{MB}$ and $\mathrm{CR}$ removal efficiency by using the AFGM, which seems does not have any significant interaction effects.

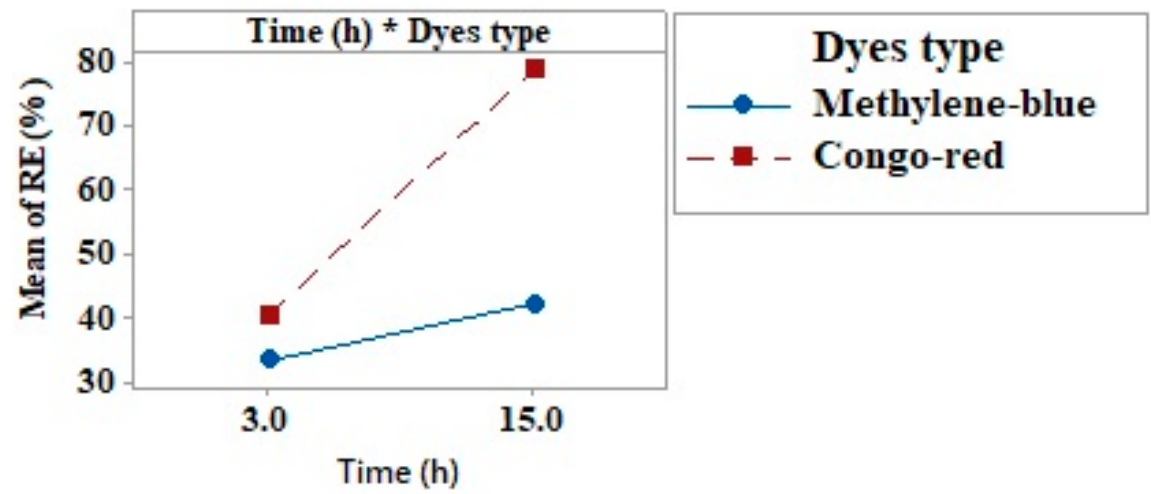

Figure 7. Plot of the interaction effects for the for the MB and CR adsorption by the AFGM.

\section{Pareto Chart}

The Pareto chart in which a student $t$-test was estimated to determine the significance difference of different parameters from zero $[49,50]$. At sixteen degree of freedom and 
$95 \%$ confidence intervals, the $t$-value reference line was 3.182 (Figure 8). Previously, it was mentioned that all data that exceed the reference line are significant data whilst, the data that not-exceed the reference line are non-significant. Accordingly, the dyes concentration (B), time (A), and pollutant type (C) are significant factors that may have an effect on the dye's removal efficiency.

Term

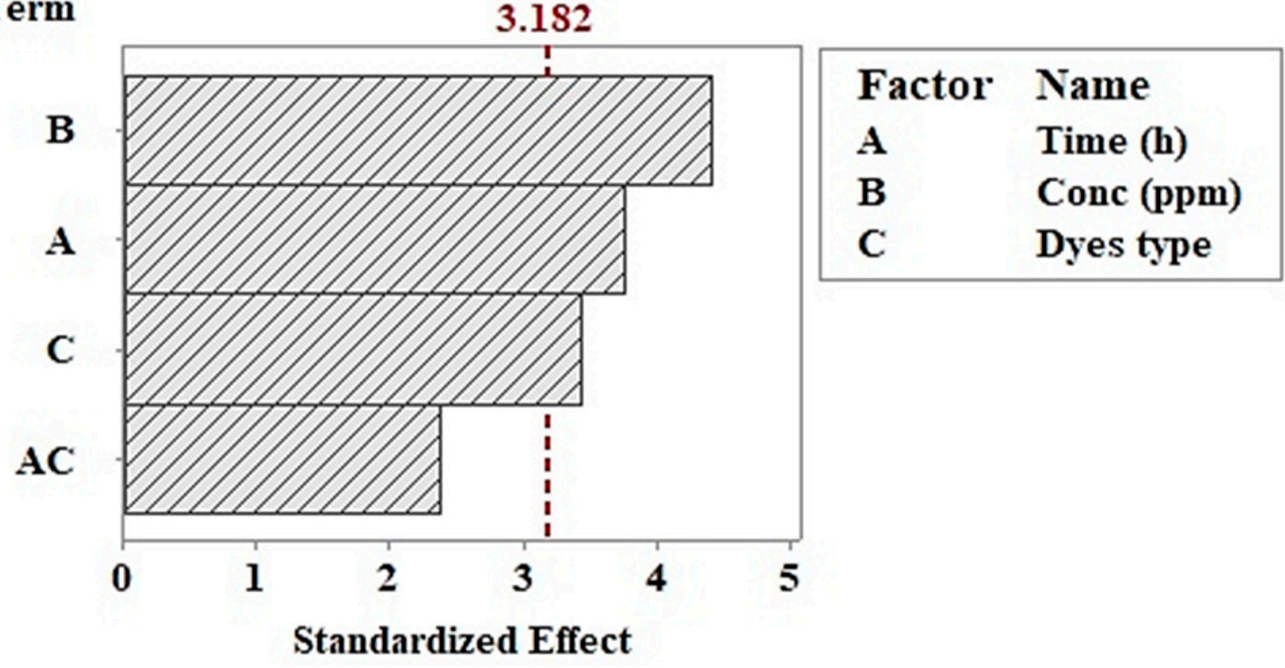

Figure 8. Pareto chart for the MB and CR adsorption by the AFGM.

Normal Probability Plot

Figure 9 stated that, both of (B), (A), and (C) are real factors and they effect on the MB and $C R$ removal percent because; they were positioned away from the plotted line. The points that lie on the left of the plotted line had a negative effect on the removal process (B) nevertheless, the points that lie on the right of the line had a positive effect on the dyes removal efficiency (A), and (C) [51,52]. All these results confirm the results obtained previously from Pareto, main, and interaction effects plot.

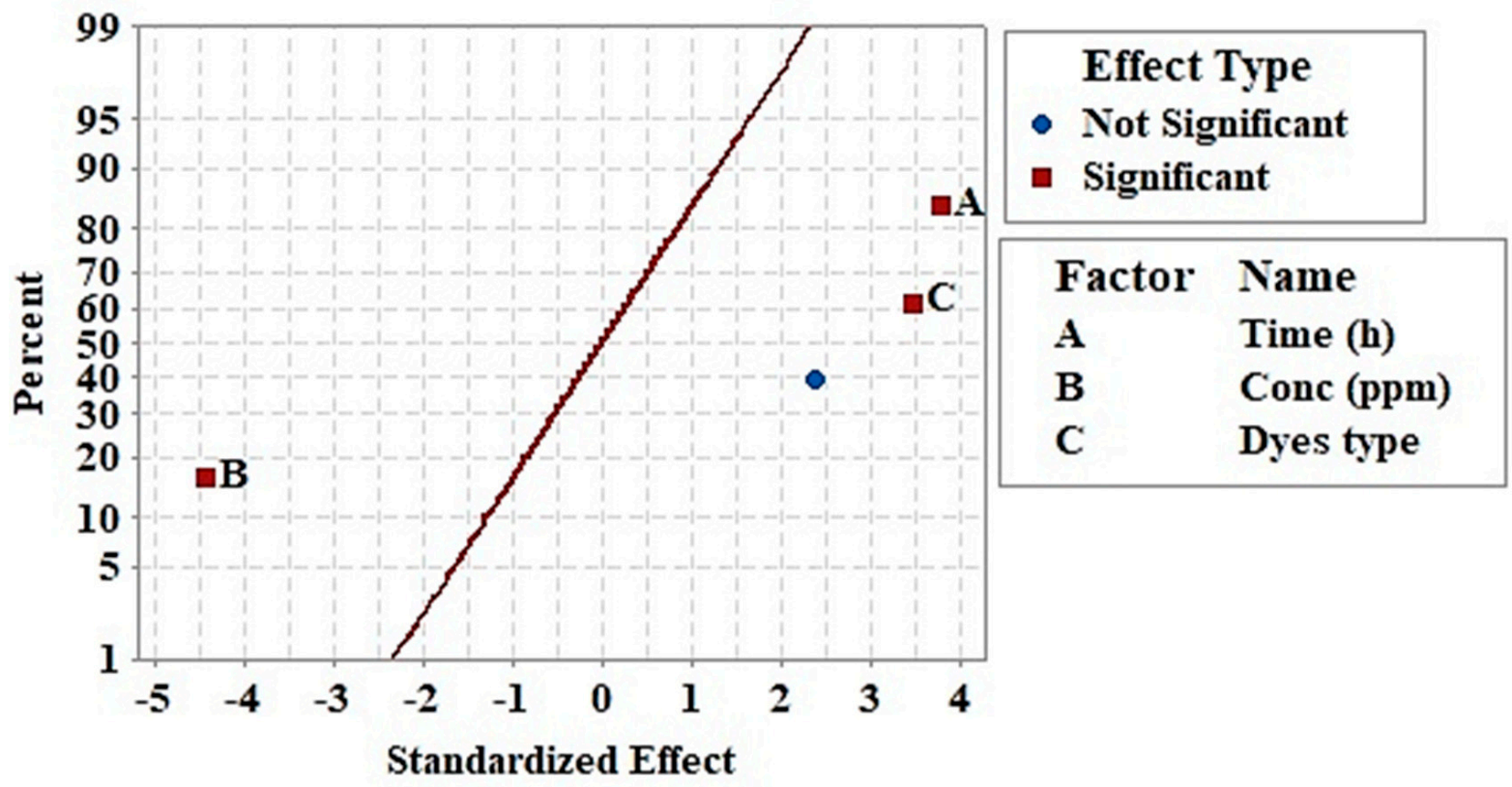

Figure 9. Plot of the normal probability for the MB and CR adsorption by the AFGM. 


\section{Response Optimizer}

A response optimizer is a tool that predicted the effect of a group of factors or parameters on a response. In this study, the removal efficiency was studied by noticing the effect of time, dyes concentration and dyes type on the dye's removal efficiency. Where, the removal efficiency of $92.6 \%$ was obtained after $15 \mathrm{~h}$ contact time, static condition, and $\mathrm{CR}$ concentration of $50 \mathrm{mg} / \mathrm{L}$ with a degree of accuracy of 1 (Figure 10).

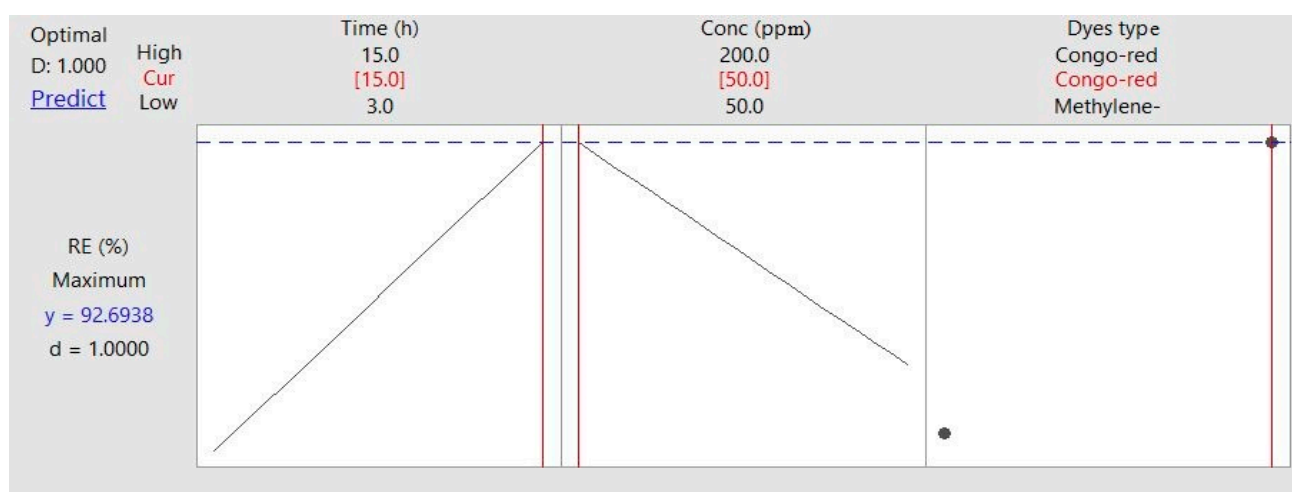

Figure 10. Response optimizer of $\mathrm{MB}$ and $\mathrm{CR}$ removal process by the AFGM.

\subsection{Langmuir and Freundlich Isotherms}

Adsorption isotherm models were demonstrated by applying the two linear equations, Langmuir and Freundlich. The Langmuir model was represented by a linear plot between a specific sorption (Ce/Qe) and the equilibrium concentration (Ce) for MB and CR dyes adsorption by AFGM. The Linear Langmuir and Freundlich isotherms plot and the calculated results were showed in Figure 11a,b and Table 5. In the current work, the adsorption nature of both MB and CR by AFGM exhibited by the Langmuir isotherm model. This can be attributed to the high $\mathrm{R}^{2}$ that was noticed in both states. Moreover, these results were due to the adsorbent surface homogenous nature. The dyes adsorbed completely to the AFGM surface "active sites" until no further adsorption can be noticed and no noticeable further interaction between the adsorbed dyes molecules and the neighboring active sites [50,51]. Table 6 compares de adsorption capacity of AFGM to the MB and CR to those obtained with other adsorption materials.

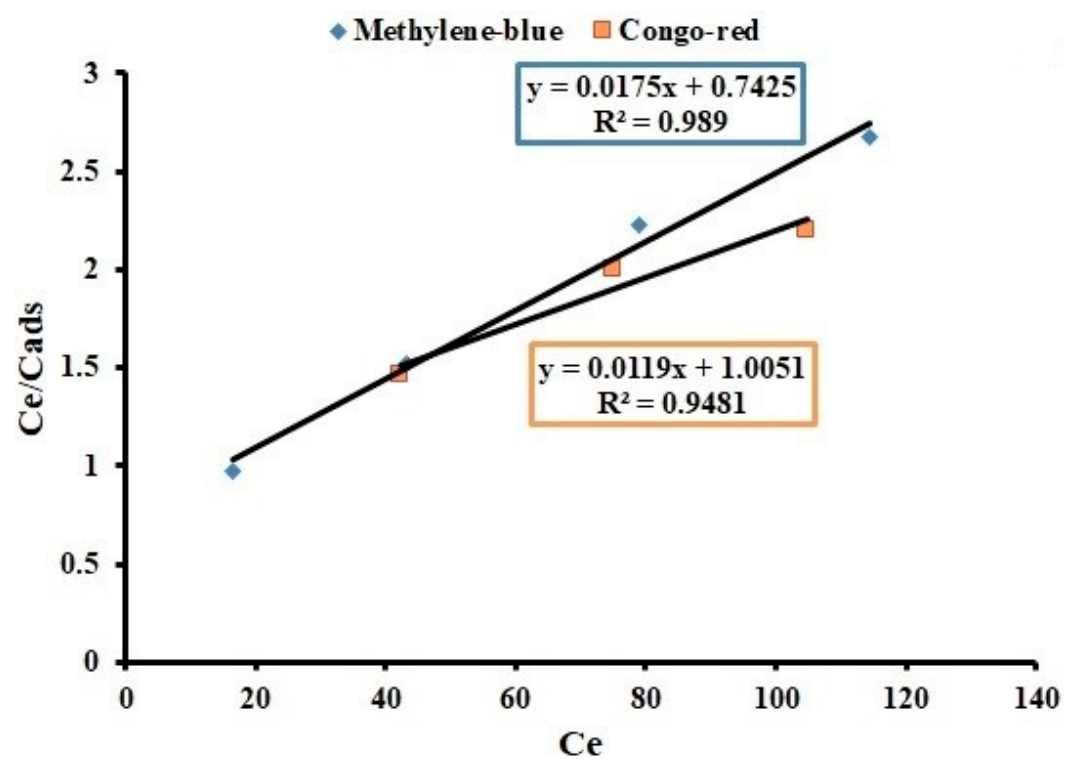

(a)

Figure 11. Cont. 


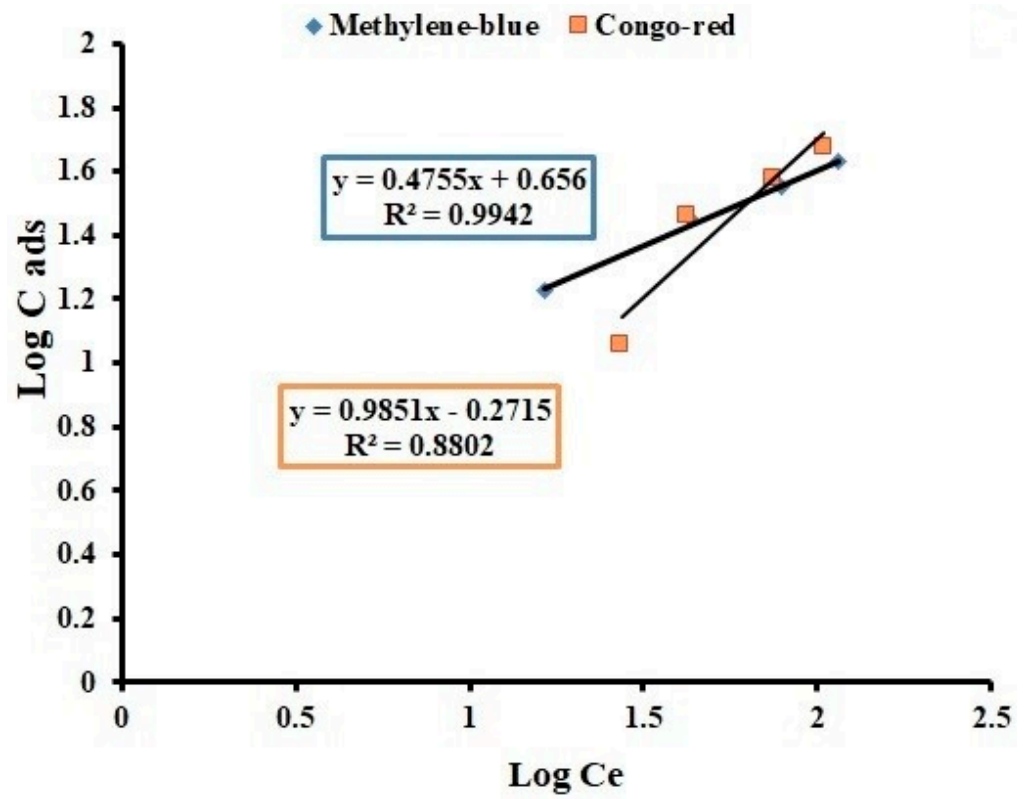

(b)

Figure 11. Langmuir (a) and Freundlich (b) isotherm for the MB and CR adsorption by the AFGM.

Table 5. Langmuir and Freundlich Isotherm parameters for MB and CR adsorptions by AFGM.

\begin{tabular}{|c|c|c|c|c|c|c|}
\hline Model & \multicolumn{6}{|c|}{ Parameters } \\
\hline \multirow{3}{*}{ Langmuir } & \multicolumn{2}{|c|}{ Qmax (mg/g) } & \multicolumn{2}{|c|}{$\mathbf{b}$} & \multicolumn{2}{|c|}{$R^{2}$} \\
\hline & MB & CR & MB & $\mathrm{CR}$ & MB & CR \\
\hline & 57.14 & 84.03 & 0.0235 & 0.011 & 0.989 & 0.9481 \\
\hline \multirow{3}{*}{ Freundlich } & \multicolumn{2}{|c|}{$\mathbf{N}$} & \multicolumn{2}{|c|}{ K } & \multicolumn{2}{|c|}{$\mathbf{R}^{2}$} \\
\hline & MB & CR & $\mathrm{MB}$ & CR & $\mathrm{MB}$ & CR \\
\hline & 2.01 & 1.015 & 3.479 & 2.6 & 0.9942 & 0.8802 \\
\hline
\end{tabular}

$\mathrm{R}^{2}$, determination coefficient. $\mathrm{MB}$, methylene blue. $\mathrm{CR}$, Congo red.

Table 6. Comparison between different sorbent materials for MB and CR dyes adsorption capacities.

\begin{tabular}{ccccc}
\hline Sorbent Materials & Dye & Conc (mg/L) & $\begin{array}{c}\text { Adsorption Capacity } \\
\text { (Qe mg/g) }\end{array}$ & References \\
\hline Acrylic fiber membrane & MB & 100 & 57.14 & Current study \\
Acrylic fiber membrane & CR & 100 & 84.03 & Current study \\
Zeolite & MB & - & 10.82 & {$[53]$} \\
Rice husk & MB & $10-125$ & 40.58 & {$[54]$} \\
CB-CTAB & CR & 20 & 19.15 & {$[55]$} \\
Sulfated AP & CR & 10 & 67.18 & {$[56]$} \\
Wheat straw biochar powder & MB & $5-80$ & 10.4 & {$[57]$} \\
Freeze-dried agarose gel & MB & - & 66.97 & {$[58]$} \\
Sulfated AP-g-PAM & CR & 10 & 35.3 & {$[56]$} \\
Pinus brutia & CR & 50 & {$[59]$} & \\
\hline
\end{tabular}

\subsection{Kinetics}

The study of equilibrium analysis is an important factor to demonstrate the AFGM affinity and capacity. The determination coefficient $\left(R^{2}\right)$ (Figure 12) and the calculated and experimental Qe values (Table 7) show that the pseudo-second-order model suited well with the experimental data than the pseudo-first-order model in two states of adsorption experiments. Previous studies revealed that MB and CR adsorption by the grafted membrane agreed well with pseudo-second-order reaction [60]. 


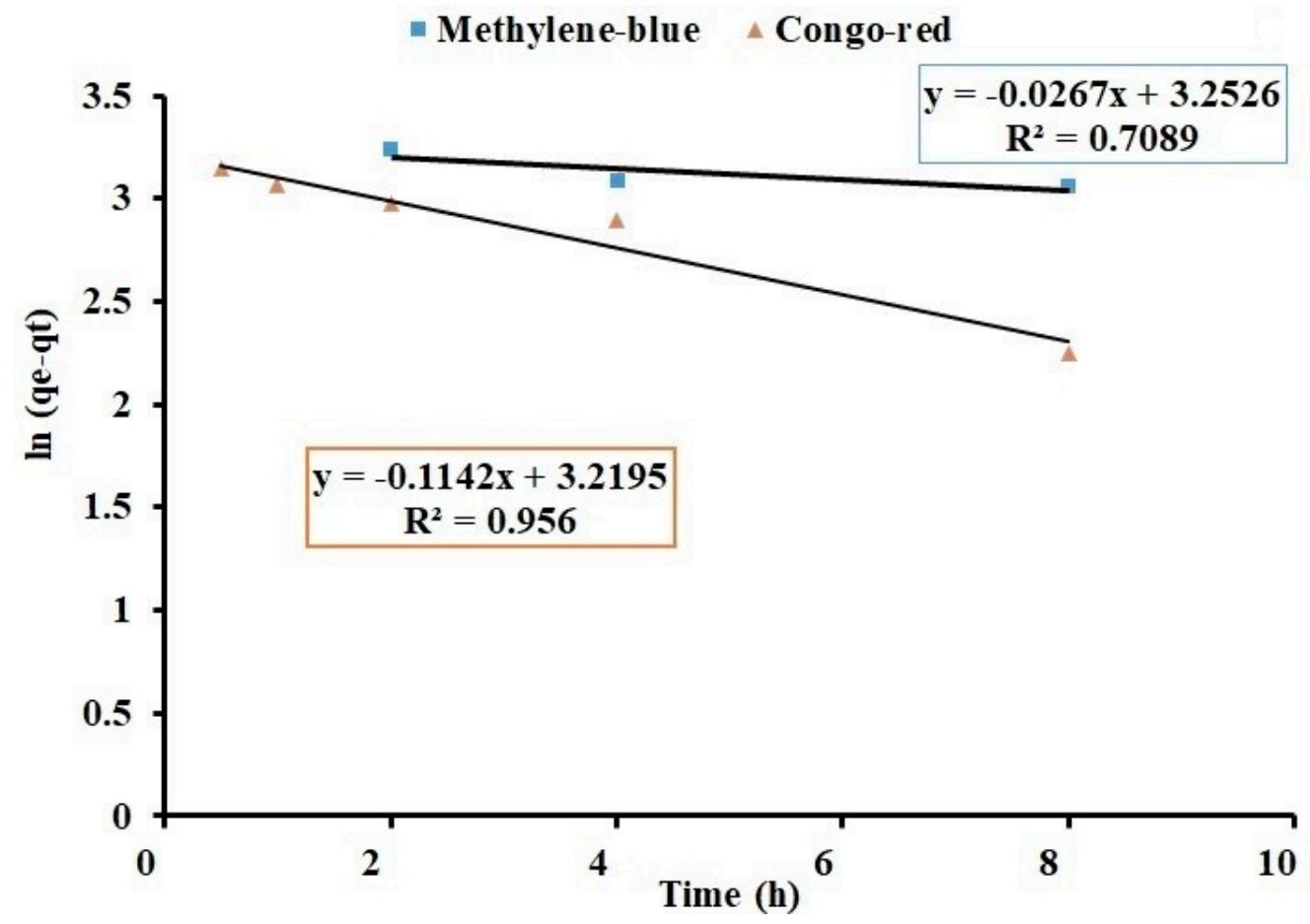

(a)

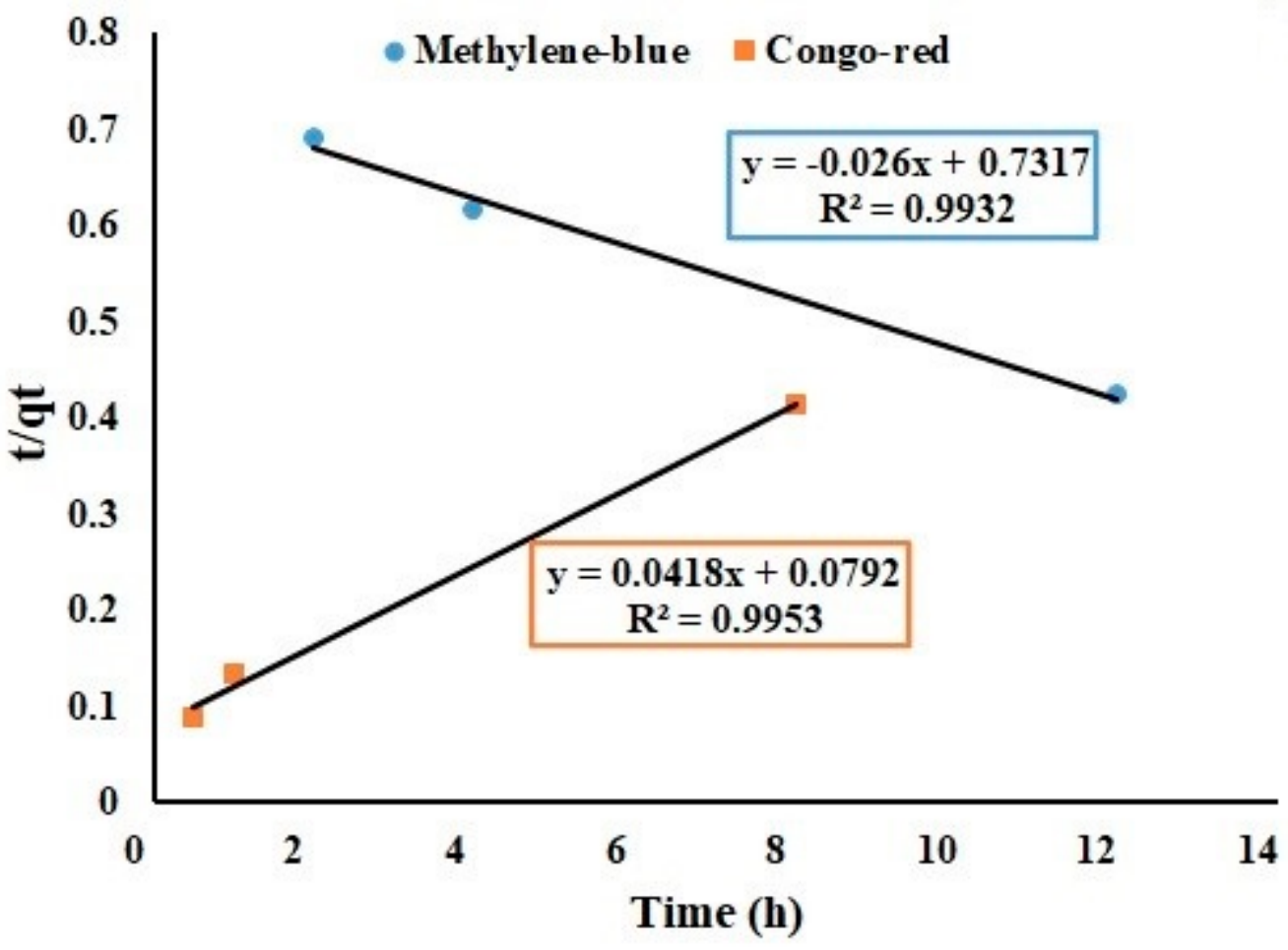

(b)

Figure 12. The pseudo first-order reaction (a) and pseudo second order reaction (b) for methylene blue and Congo red dyes adsorption by AFGM. 
Table 7. Kinetic parameters for MB and CR adsorption by AFGM.

\begin{tabular}{|c|c|c|c|c|c|c|c|c|}
\hline Model & \multicolumn{8}{|c|}{ Parameters } \\
\hline \multirow{3}{*}{$\begin{array}{l}\text { 1st order } \\
\text { Kinetics }\end{array}$} & \multicolumn{2}{|c|}{ Qe calc. } & \multicolumn{2}{|c|}{ Qe exper. } & \multicolumn{2}{|c|}{$\mathbf{K}$} & \multicolumn{2}{|c|}{$\mathbf{R}^{2}$} \\
\hline & MB & CR & $\mathrm{MB}$ & CR & MB & CR & MB & CR \\
\hline & 1788.9 & 1657.6 & 28.4 & 28.9 & 0.06149 & 0.258 & 0.7089 & 0.956 \\
\hline \multirow{3}{*}{$\begin{array}{l}\text { 2nd order } \\
\text { kinetics }\end{array}$} & \multicolumn{2}{|c|}{ Qe calc. } & \multicolumn{2}{|c|}{ Qe exper. } & \multicolumn{2}{|c|}{$\mathbf{K}$} & \multicolumn{2}{|c|}{$\mathbf{R}^{2}$} \\
\hline & $\mathrm{MB}$ & CR & $\mathrm{MB}$ & CR & MB & CR & $\mathrm{MB}$ & CR \\
\hline & 38.46 & 23.92 & 28.4 & 28.9 & 0.00092 & 0.02206 & 0.9932 & 0.9953 \\
\hline
\end{tabular}

$\mathrm{R}^{2}$, determination coefficient. MB, Methylene blue. $\mathrm{CR}$, Congo red.

\subsection{Regeneration Studies}

Re-use experiments were performed for the AFGM, which stated that, $88 \%$, and $68 \%$ of their removal capacity for the $\mathrm{CR}$, and the $\mathrm{MB}$ dyes, respectively. The previous results were demonstrated after the recovery process by $25 \%$ aqueous ethanol solution after 5 cycles of adsorption and desorption. Additionally, the results indicated that, the AFGM remove $\mathrm{CR}$ with high percentage than $\mathrm{MB}$ removal, which may be due to the cationic nature of the adsorptive membrane that combined easily with anionic dye (CR) see Figure 13. These results indicated the stability of the AFGM in adsorption of dye from wastewater.

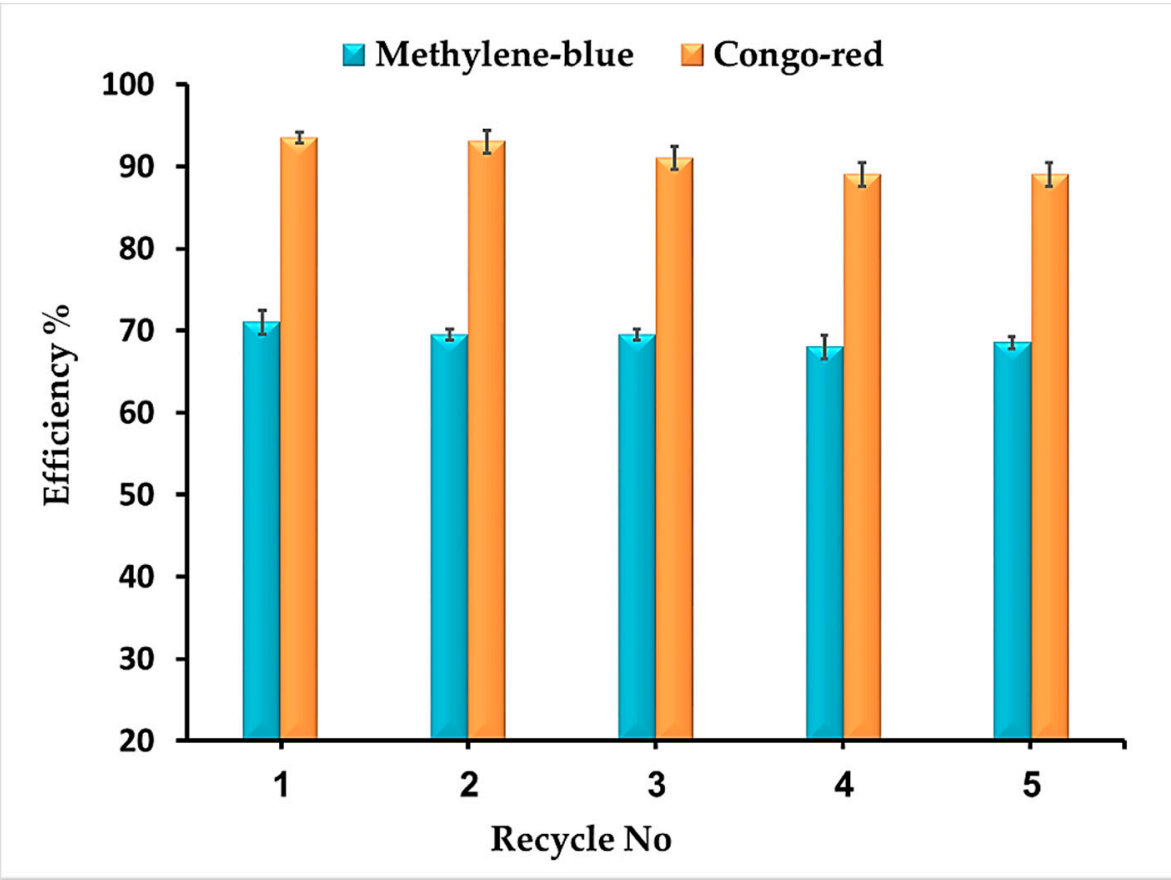

Figure 13. Application of the AFGM in different adsorption desorption cycles, $n=3$.

\section{Conclusions}

During this study, the acrylic fibers waste was recycled and converted onto a membrane then grafted using $p$-phenylenediamine forming AFGM that has adsorption capacity towards cationic and anionic dyes. The dye's removal efficiency was successfully assessed and optimized through some preliminary experiments and full factorial design. The results stated that, methylene blue has a removal efficiency of $61 \%$ and an adsorption capacity of 56.06 at $50 \mathrm{mg} / \mathrm{L}$ conc, after $15 \mathrm{~h}$ contact time in a static mode. Whereas Congo red removal efficiency of $86 \%$ and adsorption capacity of 92.69 at $50 \mathrm{mg} / \mathrm{L}$ conc. after $15 \mathrm{~h}$ contact time in a static mode was achieved. From these results, it could be concluded that, the AFGM showed a good adsorbent capacity for dyes removal and it has shown higher affinity for anionic dyes (Congo red) than for cationic one (methylene blue). Furthermore, the data 
was fitted well with Langmuir isotherm and second order kinetics model. The three Rs processes "' were successfully applied where nearly $70 \%$ and $93 \%$ removal capacities of the Methylene blue and the Congo red dyes, respectively after the recovery process with $25 \%$ aqueous ethanol solution. Previous result stated the applicability of this membrane in industrial wastewater treatment. For further studies in the future, several materials could be investigated in the static model in order to achieve higher dyes adsorption capacity with an applicable low cost.

Author Contributions: Conceptualization, A.L., A.E.A. and S.H.; methodology, A.L., A.E.A., G.S., T.Y. and S.H.; software, A.L., A.E.A., G.S., E.A. and S.H.; validation, A.L., A.E.A., G.S., E.A., A.A.G., T.Y. and S.H.; formal analysis, A.L., A.E.A., T.Y. and S.H.; investigation, A.L., A.E.A., T.Y. and S.H.; resources, A.L., A.E.A., G.S., E.A., A.A.G., T.Y. and S.H.; writing-original draft preparation, A.L., A.E.A., T.Y. and S.H.; writing-review and editing, A.L., A.E.A., G.S., E.A., A.A.G., T.Y. and S.H.; project administration, A.L., A.E.A., G.S., S.H., E.A., A.A.G. and T.Y.; funding acquisition, E.A., A.A.G. All authors have read and agreed to the published version of the manuscript.

Funding: This research received no external funding.

Institutional Review Board Statement: Not applicable.

Informed Consent Statement: Not applicable.

Data Availability Statement: No new data were created or analyzed in this study. Data sharing is not applicable to this article.

Acknowledgments: We thank the researchers at Taif University, Taif, Saudi Arabia (supporting project number: TURSP-2020/13)).

Conflicts of Interest: The authors declare no conflict of interest.

\section{References}

1. Aksakal, O.; Ucun, H. Equilibrium, kinetic and thermodynamic studies of the biosorption of textile dye (Reactive Red 195) onto Pinus sylvestris L. J. Hazard. Mater. 2010, 181, 666-672. [CrossRef] [PubMed]

2. Soliman, M.; Elkelish, A.; Souad, T.; Alhaithloul, H.; Farooq, M. Brassinosteroid Seed Priming with Nitrogen Supplementation Improves Salt Tolerance in Soybean. Physiol. Mol. Biol. Plants 2020. [CrossRef]

3. Abdel-Azeem, A.; Nada, A.; O’Donovan, A.; Kumar Thakur, V.; Elkelish, A. Mycogenic Silver Nanoparticles from Endophytic Trichoderma Atroviride with Antimicrobial Activity. J. Renew. Mater. 2019, 7, 171-185. [CrossRef]

4. Salem, S.S.; El-Belely, E.F.; Niedbała, G.; Alnoman, M.M.; Hassan, S.E.-D.; Eid, A.M.; Shaheen, T.I.; Elkelish, A.; Fouda, A. Bactericidal and In-Vitro Cytotoxic Efficacy of Silver Nanoparticles (Ag-NPs) Fabricated by Endophytic Actinomycetes and Their Use as Coating for the Textile Fabrics. Nanomaterials 2020, 10, 2082. [CrossRef] [PubMed]

5. Moghazy, R.M.; Labena, A.; Husien, S.; Mansor, E.S.; Abdelhamid, A.E. Neoteric approach for efficient eco-friendly dye removal and recovery using algal-polymer biosorbent sheets: Characterization, factorial design, equilibrium and kinetics. Int. J. Biol. Macromol. 2020, 157, 494-509. [CrossRef]

6. Abdelhamid, A.E.; El-Sayed, A.A.; Khalil, A.M. Polysulfone nanofiltration membranes enriched with functionalized graphene oxide for dye removal from wastewater. J. Polym. Eng. 2020, 40, 833-841. [CrossRef]

7. Husien, S.; Labena, A.; El-Belely, E.; Mahmoud, H.; Hamouda, A. Application of Nostoc sp. for hexavalent chromium [Cr(VI)] removal: Planktonic and biofilm. Int. J. Environ. Anal. Chem. 2020, 1-22. [CrossRef]

8. Abd El-Ghaffar, M.; Elawady, M.M.; Rabie, A.M.; Abdelhamid, A.E.J.J.o.P.R. Enhancing the RO performance of cellulose acetate membrane using chitosan nanoparticles. J. Polym. Res. 2020, 27, 1-12.

9. Badawi, A.K.; Zaher, K. Hybrid treatment system for real textile wastewater remediation based on coagulation/flocculation, adsorption and filtration processes: Performance and economic evaluation. J. Water Process Eng. 2021, 40, 101963. [CrossRef]

10. Zhu, M.-X.; Lee, L.; Wang, H.-H.; Wang, Z. Removal of an anionic dye by adsorption/precipitation processes using alkaline white mud. J. Hazard. Mater. 2007, 149, 735-741. [CrossRef] [PubMed]

11. Yao, L.; Zhang, L.; Wang, R.; Chou, S.; Dong, Z. A new integrated approach for dye removal from wastewater by polyoxometalates functionalized membranes. J. Hazard. Mater. 2016, 301, 462-470. [CrossRef]

12. El-Shahat, M.; Abdelhamid, A.E.; Abdelhameed, R.M. Capture of iodide from wastewater by effective adsorptive membrane synthesized from MIL-125-NH2 and cross-linked chitosan. Carbohydr. Polym. 2020, 231, 115742. [CrossRef]

13. Elawwad, A.; Karam, A.; Zaher, K. Using an algal photo-bioreactor as a polishing step for secondary treated wastewater. Pol. J. Environ. Stud. 2017, 26, 1493-1500. [CrossRef]

14. Karam, A.; Bakhoum, E.S.; Zaher, K. Coagulation/flocculation process for textile mill effluent treatment: Experimental and numerical perspectives. Int. J. Sustain. Eng. 2020, 1-13. [CrossRef] 
15. Patel, H.; Vashi, R. Removal of Congo Red dye from its aqueous solution using natural coagulants. J. Saudi Chem. Soc. 2012, 16, 131-136. [CrossRef]

16. Das, A.; Adhikari, S.; Kundu, P. Bioremediation of Wastewater Using Microalgae. In Environmental Biotechnology For Soil and Wastewater Implications on Ecosystems; Springer: Berlin/Heidelberg, Germany, 2019; pp. 55-60.

17. Karam, A.; Zaher, K.; Mahmoud, A.S. Comparative studies of using nano zerovalent iron, activated carbon, and green synthesized nano zerovalent iron for textile wastewater color removal using artificial intelligence, regression analysis, adsorption isotherm, and kinetic studies. Air Soil Water Res. 2020, 13, 1178622120908273. [CrossRef]

18. Badawi, A.K.; Bakhoum, E.S.; Zaher, K. Engineering Sustainable Evaluation of Using Nano Zero-Valent Iron and Activated Carbon for Real Textile Effluent Remediation. Arab. J. Sci. Eng. 2021, 1-16. [CrossRef]

19. Mansour, T.; Labena, A.; Maziad, N.; Hessin, S. Radiation Copolymerization of PVA/Malic acid/HEMA/Macro-algal (Sargassum sp.) Biomass for Removal of Hexavalent Chromium. Egypt. J. Chem. 2019. [CrossRef]

20. Xia, L.; Zhou, S.; Zhang, C.; Fu, Z.; Wang, A.; Zhang, Q.; Wang, Y.; Liu, X.; Wang, X.; Xu, W. Environment-friendly Juncus effusus-based adsorbent with a three-dimensional network structure for highly efficient removal of dyes from wastewater. J. Clean. Prod. 2020, 259, 120812. [CrossRef]

21. Zidan, T.; Abdelhamid, A.E.; Zaki, E. N-Aminorhodanine modified chitosan hydrogel for antibacterial and copper ions removal from aqueous solutions. Int. J. Biol. Macromol. 2020. [CrossRef]

22. Mansor, E.S.; Labena, A.; Moghazy, R.M.; Abdelhamid, A.E. Advanced eco-friendly and adsorptive membranes based on Sargassum dentifolium for heavy metals removal, recovery and reuse. J. Water Process. Eng. 2020, 37, 101424. [CrossRef]

23. Abdelhamid, A.E.; Labena, A.; Mansor, E.S.; Husien, S.; Moghazy, R.M. Highly efficient adsorptive membrane for heavy metal removal based on Ulva fasciata biomass. Biomass Convers. Biorefinery 2021. [CrossRef]

24. Cseri, L.; Topuz, F.; Abdulhamid, M.A.; Alammar, A.; Budd, P.M.; Szekely, G. Electrospun Adsorptive Nanofibrous Membranes from Ion Exchange Polymers to Snare Textile Dyes from Wastewater. Adv. Mater. Technol. 2021, 2000955. [CrossRef]

25. Hardian, R.; Liang, Z.; Zhang, X.; Szekely, G. Artificial intelligence: The silver bullet for sustainable materials development. Green Chem. 2020, 22, 7521-7528. [CrossRef]

26. Akbari, A. Novel membrane adsorbents prepared by waste fibers of mechanized carpet for Persian Orange $X$ removal. Environ. Nanotechnol. Monit. Manag. 2017, 8, 209-218.

27. Deng, S.; Bai, R.; Chen, J.P. Aminated polyacrylonitrile fibers for lead and copper removal. Langmuir 2003, 19, 5058-5064. [CrossRef]

28. Mirzababaei, M.; Miraftab, M.; Mohamed, M.; McMahon, P. Impact of carpet waste fibre addition on swelling properties of compacted clays. Geotech. Geol. Eng. 2013, 31, 173-182. [CrossRef]

29. Orabi, A.H.; Abdelhamid, A.E.-S.; Salem, H.M.; Ismaiel, D.A.J.J.o.R.; Chemistry, N. New adsorptive composite membrane from recycled acrylic fibers and Sargassum dentifolium marine algae for uranium and thorium removal from liquid waste solution. J. Radioanal. Nucl. Chem. 2020, 326, 1233-1247. [CrossRef]

30. Wang, B.; Chen, P.-Y.; Zhao, R.-X.; Zhang, L.; Chen, Y.; Yu, L.-P. Carbon-dot modified polyacrylonitrile fibers: Recyclable materials capable of selectively and reversibly adsorbing small-sized anionic dyes. Chem. Eng. J. 2020, 391, 123484. [CrossRef]

31. Abdelhamid, A.E.; Khalil, A.M. Polymeric membranes based on cellulose acetate loaded with candle soot nanoparticles for water desalination. J. Macromol. Sci. Part A 2019, 56, 153-161. [CrossRef]

32. Abdelhamid, A.E.; Elawady, M.M.; El-Ghaffar, M.A.A.; Rabie, A.M.; Larsen, P.; Christensen, M.L. Surface modification of reverse osmosis membranes with zwitterionic polymer to reduce biofouling. Water Sci. Technol. Water Supply 2015, 15, 999-1010. [CrossRef]

33. Abdelwahab, N.; Al-Ashkar, E.; El-Ghaffar, M.A. Preparation and characterization of eco-friendly poly (p-phenylenediamine) and its composite with chitosan for removal of copper ions from aqueous solutions. Trans. Nonferrous Met. Soc. China 2015, 25, 3808-3819. [CrossRef]

34. Rabiee, H.; Vatanpour, V.; Farahani, M.H.D.A.; Zarrabi, H. Improvement in flux and antifouling properties of PVC ultrafiltration membranes by incorporation of zinc oxide ( $\mathrm{ZnO})$ nanoparticles. Sep. Purif. Technol. 2015, 156, 299-310. [CrossRef]

35. Li, Y.; Su, Y.; Zhao, X.; He, X.; Zhang, R.; Zhao, J.; Fan, X.; Jiang, Z. Antifouling, high-flux nanofiltration membranes enabled by dual functional polydopamine. Acs Appl. Mater. Interfaces 2014, 6, 5548-5557. [CrossRef]

36. Marrez, D.A.; Abdelhamid, A.E.; Darwesh, O.M. Eco-friendly cellulose acetate green synthesized silver nano-composite as antibacterial packaging system for food safety. Food Packag. Shelf Life 2019, 20, 100302. [CrossRef]

37. Cao, B.; Adutwum, L.A.; Oliynyk, A.O.; Luber, E.J.; Olsen, B.C.; Mar, A.; Buriak, J.M. How To Optimize Materials and Devices via Design of Experiments and Machine Learning: Demonstration Using Organic Photovoltaics. ACS Nano 2018, 12, 7434-7444. [CrossRef]

38. Langmuir, I. The adsorption of gases on plane surfaces of glass, mica and platinum. J. Am. Chem. Soc. 1918, 40, 1361-1403. [CrossRef]

39. Freundlich, H. Über die adsorption in lösungen. Zeitschrift für physikalische Chemie 1907, 57, 385-470. [CrossRef]

40. Sarioglu, M.; Atay, U.J.G.N.J. Removal of Methylene blue by using biosolid. Glob. NEST J. 2006, 8, 113-120.

41. Song, J.; Kong, H.; Jang, J. Adsorption of heavy metal ions from aqueous solution by polyrhodanine-encapsulated magnetic nanoparticles. J. Colloid Interface Sci. 2011, 359, 505-511. [CrossRef] 
42. Pigorsch, E.; Elhaddaoui, A.; Turrell, S. Spectroscopic study of $\mathrm{pH}$ and solvent effects on the structure of Congo red and its binding mechanism to amyloid-like proteins. Spectrochim. Acta Part A Mol. Spectrosc. 1994, 50, 2145-2152. [CrossRef]

43. Fu, Y.; Viraraghavan, T. Removal of Congo Red from an aqueous solution by fungus Aspergillus niger. Adv. Environ. Res. 2002, 7, 239-247. [CrossRef]

44. El-Wakeel, S.; Moghazy, R.; Labena, A.; Husien, S. Algal biosorbent as a basic tool for heavy metals removal; the first step for further applications. J. Mater. Environ. Sci. 2019, 10, 75-87.

45. Husien, S.; Labena, A.; El-Belely, E.; Mahmoud, H.M.; Hamouda, A.S. Adsorption studies of hexavalent chromium [Cr (VI)] on micro-scale biomass of Sargassum dentifolium, Seaweed. J. Environ. Chem. Eng. 2019, 7, 103444. [CrossRef]

46. Husien, S.; Labena, A.; El-Belely, E.; Mahmoud, H.M.; Hamouda, A.S. Absorption of hexavalent chromium by green micro algae Chlorella sorokiniana: Live planktonic cells. Water Pract. Technol. 2019. [CrossRef]

47. Moghazy, R.M. Activated biomass of the green microalga Chlamydomonas variabilis as an efficient biosorbent to remove methylene blue dye from aqueous solutions. Water SA 2019, 45, 20-28. [CrossRef]

48. Tuzen, M.; Sarı, A.; Saleh, T.A. Response surface optimization, kinetic and thermodynamic studies for effective removal of rhodamine B by magnetic AC/CeO2 nanocomposite. J. Environ. Manag. 2018, 206, 170-177. [CrossRef]

49. Saad, M.; Tahir, H.; Khan, J.; Hameed, U.; Saud, A. Synthesis of polyaniline nanoparticles and their application for the removal of Crystal Violet dye by ultrasonicated adsorption process based on Response Surface Methodology. Ultrason. Sonochem. 2017, 34, 600-608. [CrossRef]

50. Saadat, S.; Karimi-Jashni, A. Optimization of $\mathrm{Pb}$ (II) adsorption onto modified walnut shells using factorial design and simplex methodologies. Chem. Eng. J. 2011, 173, 743-749. [CrossRef]

51. Saad, M.; Tahir, H.; Ali, D. Green synthesis of Ag-Cr-AC nanocomposites by Azadirachta indica and its application for the simultaneous removal of binary mixture of dyes by ultrasonicated assisted adsorption process using Response Surface Methodology. Ultrason. Sonochem. 2017, 38, 197-213. [CrossRef]

52. Ponnusami, V.; Krithika, V.; Madhuram, R.; Srivastava, S. Biosorption of reactive dye using acid-treated rice husk: Factorial design analysis. J. Hazard. Mater. 2007, 142, 397-403. [CrossRef]

53. Woolard, C.; Strong, J.; Erasmus, C. Evaluation of the use of modified coal ash as a potential sorbent for organic waste streams. Appl. Geochem. 2002, 17, 1159-1164. [CrossRef]

54. Cengiz, S.; Cavas, L. Removal of methylene blue by invasive marine seaweed: Caulerpa racemosa var. cylindracea. Bioresour. Technol. 2008, 99, 2357-2363. [CrossRef] [PubMed]

55. Rouf, S.; Nagapadma, M.; Rao, R.R. Removal of harmful textile dye congo red from aqueous solution using chitosan and chitosan beads modified with CTAB. Int. J. Eng. Res. Appl. 2015, 5, 75-82.

56. Sasmal, D.; Maity, J.; Kolya, H.; Tripathy, T. Study of congo red dye removal from its aqueous solution using sulfated acrylamide and N, N- dimethyl acrylamide grafted amylopectin. J. Water Process. Eng. 2017, 18, 7-19. [CrossRef]

57. Li, G.; Zhu, W.; Zhang, C.; Zhang, S.; Liu, L.; Zhu, L.; Zhao, W. Effect of a magnetic field on the adsorptive removal of methylene blue onto wheat straw biochar. Bioresour. Technol. 2016, 206, 16-22. [CrossRef]

58. Seow, W.Y.; Hauser, C.A.E. Freeze-dried agarose gels: A cheap, simple and recyclable adsorbent for the purification of methylene blue from industrial wastewater. J. Environ. Chem. Eng. 2016, 4, 1714-1721. [CrossRef]

59. Omar, H.; El-Gendy, A.; Al-Ahmary, K. Bioremoval of toxic dye by using different marine macroalgae. Turk. J. Bot. 2018, 42, 15-27. [CrossRef]

60. Kavitha, D.; Namasivayam, C. Experimental and kinetic studies on methylene blue adsorption by coir pith carbon. Bioresour. Technol. 2007, 98, 14-21. [CrossRef] 